\title{
Rote Memorization of Vocabulary and Vocabulary Development
}

\author{
Weidong Yang (Corresponding author) \\ Foreign Languages Department, China University of Petroleum, Beijing \\ 18 Fuxue Road, Changping District, Beijing 102249, China \\ Tel: 86-10-8973-3282Ｅ-mail: clarkdream@sina.com \\ Weiping Dai \\ Foreign Languages Department, China University of Petroleum, Beijing \\ 18 Fuxue Road, Changping District, Beijing 102249, China \\ Tel: 86-10-8973-3282 E-mail: dwping@cup.edu.cn
}

Received: July 15, 2011

Accepted: August 26, 2011

Published: December 1, 2011

doi:10.5539/elt.v4n4p61

URL: http://dx.doi.org/10.5539/elt.v4n4p61

\begin{abstract}
Rote memorization of vocabulary has long been a common way for Chinese students to learn lexical items. Cultural, educational background and traditional teaching practice in China are identified to be the factors that contribute to many students' heavy reliance on memorization as their sole approach to vocabulary learning. In addition to rote memorization which has been proved useful and effective in the Chinese ELT context, this paper suggests that students be presented with vocabulary learning strategies and be taught how to build vocabulary through other useful learning methods.
\end{abstract}

Keywords: Rote memorization, Vocabulary development, Learning strategy

\section{Introduction}

Vocabulary is by far the most sizeable and unmanageable component in the learning of any language, whether foreign or one's mother tongue. No language acquisition, whether first, second, or foreign can take place without the acquisition of lexis.

Many students of English in China readily admit that they experience considerable difficulty with vocabulary, and they identify vocabulary as their greatest single source of problem in learning English. They often complain: There are so many words to learn I simply can not remember them; Those faster reading materials are full of words I don't know. How can I read them faster?

Learning words is also a time-consuming activity, and especially so as some of the words learned are forgotten quickly. Moreover, although there are some suggestions to the teacher as how to teach vocabulary, there is little guidance to the learner who asks: "How do I memorize vocabulary better?"

Research has shown that second/foreign language learners rely heavily on vocabulary knowledge, and that a lack of vocabulary knowledge is the largest obstacle for second/foreign language learners to overcome.

Students often cite vocabulary deficiencies as their biggest problem in mastering a second/foreign language. Nation noted that "teachers and researchers have seen lack of vocabulary as one of the main obstacles to progress in the receptive skills of listening and reading". Lexical ignorance is the main obstacle to advancement for the foreign language learner who has learned the phonological code of the target language and mastered the basic grammatical structures.

\section{Memorization of Vocabulary as a Focus of Lexical Learning}

"Vocabulary is not explicitly taught in many second language classes, and students are usually expected to learn vocabulary on their own without much guidance. In those instances when vocabulary is taught in second language classes, it is often taught poorly or unsystematically, for example, by presenting word list for memorization".

Memorization of vocabulary list is quite the case in vocabulary teaching practice in Chinese context. Memorization and recitation have long been used as basic language teaching practice in China. The Chinese equivalent for "memorize" translated literally means "to recite the book from memory" and literal recitation is a very common 
practice in foreign language teaching. For most Chinese students, learning English means memorizing a certain number of words a day and reciting as much of the book as possible. Talking about their English learning experience, not a few students would say "There are no methods for learning English except memorization and more memorization". Large percentages of students were unsure of many vocabulary learning strategies when they were in secondary school, and in university many remain unsure about using vocabulary learning methods other than memorization. In second school the most frequently used methods are reading textbooks, listening to the teacher, taking notes, and focusing on memorization. In other words, some traditional features of the Chines culture of learning have carried over from secondary school to university. According to the findings reported by Cortazzi \& Jin, large percentages of Chinese tertiary-level students still use memorizing words from vocabulary books and dictionaries as their main means of vocabulary learning. Vocabulary learning is viewed as nothing more than the memorization of a series of word forms with fixed meanings. Words are taught through word list (usually rote learning of a word along with Chinese equivalent). Students are supposed to learn the meanings of words by rote. Traditional method of memorizing words has been a common way for students to learn vocabulary. Many foreign language teachers who had once worked in China observed that there is a heavy reliance on rote memorization, and Chinese approaches to learning English vocabulary seem fixed on memorization of lists of individual words.

\section{Cultural and Educational Influence on Vocabulary Learning}

People in different cultures, "learn to learn" differently, e.g., some by rote memorizing, without reference to "logic", others by demonstration, without the students being required to do anything themselves. A number of studies have shown that nationality or ethnicity is one of the factors which can affect choice of language learning strategies. Studies done by Politzer \& McGroatry show that oriental learners are more inclined to use strategies including rote memorization than strategies involving communicative strategies.

O'Malley et al found resistance from Asian students to using strategies for imagery and grouping to learn vocabulary definitions. Asian students were found to rely on rote memorization strategies for vocabulary task. Cultural background, according to O'Malley \& Chamot, can be expected to play a part in using the set of learning strategies on the part of students. Part of the cultural background of students is their prior educational experiences. They found that students whose initial educational training emphasized rote memorization of curriculum content may have developed quite effective memory strategies.

The use of language learning strategies is frequently affected by language teaching methods. The longer students remained in a program, the more they tended to prefer the language learning strategies subtly suggested by that program's instructional method. Chinese students' approaches to vocabulary learning just mirror rote learning and memorization-focused instructional methods used in the language teaching practice in China.

\section{English Teaching in Chinese Context}

English language teaching in China is conducted mainly by a contingent of Chinese teachers who are trained basically in home institutions. The curriculum for English majors at the tertiary level emphasizes English language skills development. Many senior teachers feel that proficiency in English should be the sole prerequisite for holding a teaching position. The emphasis on English language skills in the current curriculum for English majors directly reflects this viewpoint. Systematic training in methodology of English language teaching is virtually non-existent in secondary level and most of the tertiary institutions.

Most of the Chinese English teachers who are already proficient in English have not yet been exposed to theories about second/foreign language acquisition and methodologies. While some may have been interested in new methodologies in teaching English, most greeted them with "We can't use that in China. The students won't like it; the senior faculty won't like it". It is difficult to change over from the traditional ways to the new ones. Therefore traditional ways of teaching still prevail.

Since most of the teachers have received no training in ELT methodology, they tend to rely on what has historically become a most salient feature of Chinese education - a methodology which stresses rote memorization and is practically devoid of opportunities for facilitating the development of other learning strategies.

Vocabulary selection is based solely on the reading texts used, and words are taught through bilingual word-lists, and memorization. In a typical grammar-translation text, the grammar rules are presented and illustrated. A list of vocabulary items are presented with their translation equivalents, and translation exercises are prescribed. For home work, students are required to memorize part of a lesson and lexical items (vocabulary lists) from the textbook. In the next class contact, teacher would test students of their memory of words of previous lesson(s).

\section{Memorization of Word Lists}

Certain elements in China traditional ELT methodology have been useful and effective, and so they should not be 
discarded altogether, for example, rote learning (memorization) of word lists. In the initial stages of second/foreign language learning, students face the problem of acquiring a fairly large number of fundamental vocabulary words in the target language. In order to accomplish this fact, students are taught to memorize native and target language word pair using vocabulary list. Current pedagogical practice does not endorse this technique since it fosters dependence on the native language as reference point. In actuality, the practice of linking target and native language vocabulary items is an entirely natural, quite probably unavoidable process, a means of integrating new information with material that is known.

Evidence has been presented that reader does not store words in two unrelated mental lexicons. Words in a second language are better retained if presented along with their native language translations which provide more association for the learner than does a definition written in the target language. Nation notes that learning words in list is an effective means for learning a large number of words in a short time. The research done by Nation (ibid) serves to underline that quantities of initial vocabulary words can be learned by methods such as rote learning both effectively and quickly.

As stated earlier, rote memorization of word lists is popular in some cultures from which second/foreign language students come, particularly Asian culture. Chinese students are consistently told by their teachers to memorize the word lists and they are accustomed to rote learning of word lists. The empirical research conducted by Qian has demonstrated the strength of decontextualized vocabulary learning in different cultural contexts. Chinese students, according to his findings, are especially at home with the decontextualized word learning. Rote memorization is also emphasized by the beginning students. "Mechanical memorization is the most efficient way of learning words, and that is what they do most of the time. They said that the more time you spend on memorizing, the more you will learn". Word lists did help Chinese students learn a lot of vocabulary words in their early stages of language learning.

\section{Learn How to Learn through Instruction}

At the intermediate-plus level, however, students should be taught to learn on their own. Students need to learn how to discover new words for themselves. Practice in the use of dictionaries should be a regular part of the language learning course. At this stage, instead of being presented ready-made list of vocabulary words, student should be required to make out his own list. First he has to decide which are the items worth learning among the vocabulary items to be encountered in each text. Secondly, he has to decide which of the, say, dozen or more definitions given for a word in the dictionary is the relevant one in the present context. Thirdly, he has to decide how best to build up his own system or inventory of vocabulary-either by topical classification, word class classification, part of speech, or simply by alphabetical order. Being able to make such decision involves the ability to observe, discriminate, select, judge, relate, and organize language data - in a word, to systematize language data, which is ability indispensable to independent second/foreign language learners.

In order to develop vocabulary students need to be armed with a wide repertoire of vocabulary learning strategies, using a series of strategies to tackle lexical problems. A knowledge of relevant affixes and roots, for instance, is valuable for a language learner to develop vocabulary. Nation stress the importance of knowledge of affixes and roots as he points out it can be used to help the learning of unfamiliar words by relating these words to known words or to known prefixes and suffixes, and it can be used as a way to check whether an unfamiliar word has been successfully guessed from context. Many English words can be learned by recognizing the basic forms of words and how they combine with certain affixes. For example, if student knows the meaning of words such as tele (far, distant), phone (sound), photo (light), graph (write, mark), he will be able to learn the words which contain these words. The awareness of the roots and affixes (Graves suggests that about 100 of the most productive affixes would be sufficient) will be a facilitating factor for him to learn those items which are made up of these components.

In light of this, Chinese students studying English should be taught from very early stage to learn those frequently used affixes that recur in a number of words and that can help them identify at least part of the meaning, thus assisting them in inferring from context the meaning of apparently new items. They should also be made aware of productive word families, and stems as well as meaningful affixes because understanding them and the way they are used to build words are extremely useful in tackling new lexical items and in building vocabulary. By becoming familiar with productive stems and affixes, students will recognize the meaning of many words as one root or affix alone would often provide a student with a clue to the meaning of dozens of words.

Additionally, the authors of present paper suggest that students be taught to learn how to augment their own vocabulary steadily and systematically.

A. They should be encouraged to begin early in their self-initiated learning activities individual lists of new words they encounter, words that interest them, and problem words which are continually tripping them up. 
B Pimsleur recommends that scheduling timely recalls and confirming correct answers will lead to better retention and slower forgetting, and in order to ensure maximum retention, timely repetitions of words learned should be arranged by the teacher. In this view, teacher should teach students to learn how to constantly repeat the word list with immediate efforts to use the words in some appropriate way.

C. Students should be encouraged to seek opportunities to use the language outside of class context. Much hearing, reading, and using of the language in informal settings or self-initiated outside activities will increase familiarity with many commonly used words.

D. Students should be able to apply word formation rules in order that their command of a word can be expanded until it covers its derivatives (e.g. vary—varied, variegated, various, variable, invariable, variant, variation, variety, etc.). In this way they may increase the number of new words learned in each text by several times.

E. Students should learn to organize their vocabulary, classifying lexical items according to subject matter, style, synonymy or antonymy. They should learn to collect common collocations in the course of their reading. Their "system" will serve as the basis for further lexical expansion.

\section{Conclusion}

Vocabulary development on the part of Chinese learners can not be reached solely through such traditional means as rote memorization of vocabulary. In order to help students facilitate vocabulary building, Chinese teachers in ELT course should weave instruction on vocabulary learning methods and strategies into regular vocabulary task-related activities. In this way learners can be armed with variety of approaches to word learning, and can be equipped with useful vocabulary learning strategies, which will surely contribute significantly to students vocabulary development.

It is clear that a learner who is constantly adding to his vocabulary knowledge is better prepared both for productive and receptive language skills. The acquisition of an adequate vocabulary is essential for successive second or foreign language use because, without an extensive vocabulary, the learner will be unable to use the structures and functions he may have learned for comprehensive communication.

\section{References}

Cortazzi, M., \& Jin, L.X. (1994). Changes in learning English vocabulary in China. In H. Coleman, \& L. Cameron (eds), Changes and Language. Clevedon: British Association for Applied Linguistics in association with Multilingual Matters. pp. 153-165

Graves, M. (1997). The roles of instruction in fostering vocabulary development. In M. Mckewn, \& M. Curtis (eds), The Nature of Vocabulary Acquisition. Hillsdale. NJ: Erlbaum. pp. 165-184

Li, J., \& Li, J. (1991). Memory strategies. Teaching English in China. ELT Newsletter. 23, 64-71

Nation, I. S. P. (1982). Beginning to learn foreign vocabulary: A review of the research. RECL Journal, 13(1). 14-36

Nation, I. S. P. (1990). Teaching and Learning Vocabulary. New York: Newbury House/Harper \& Row.

O’Malley, J. M., \& Chamot, A. U. (1990). Learning Strategies in Second Language Acquisition. Cambridge University Press.

O’Malley, J. M. et al (1985). Learning strategies application with students of English as a second language. TESOL Quarterly, 19, 285-296

Oxford, R., \& Scarcella, R. (1994). Second language vocabulary learning among adults: State of the art in vocabulary instruction. System, Vol. 22, No. 2, 231-243. http://dx.doi.org/10.1016/0346-251X(94)90059-0

Pimsleur, P. (1987). A memory schedule. Modern Language Journal, 51, 73-75. http://dx.doi.org/10.2307/321812

Politzer, R., \& Mc Groarty, M. (1985). An exploratory study of learning behavior and their relationship to gains in linguistic and communicative competence. TESOL Quarterly, 19, 103-124. http://dx.doi.org/10.2307/3586774

Qian, D. (1996). ESL vocabulary acquisition: Contextualization and decontextualization. The Canadian Modern Language Review, Vol. 53, No. 1, 120-142

Zhou, Z. J. (1995). From general English to EST: A proposal to reform China's service English teaching. ELT in China, 421-433 